\title{
The Process of weld brazing CMT (Cold Metal Transfer pulse) for assembly of the different thin sheets
}

\author{
Gheorghe Sima*, Elena Muncut, Adriana Motica and Aurelia Tanasoiu \\ Aurel Vlaicu University of Arad, Department of Automation, Industrial Engineering, Textiles and \\ Transport, Street Elena Drăgoi no. 2, RO 310068
}

\begin{abstract}
This paper describes the experimental program realized for the research of the behavior at the assembly through weld-brazing CMTP (Cold Metal Transfer pulse) of thin sheets of copper with aluminum. Four variants were chosen and studied, settling the best conditions for the assembly. They were made welded samples which were analyzed in volume terms of metallurgical and mechanical structure. It was also analyzed the influence of cooling velocity on the structure.
\end{abstract}

\section{Introduction}

To solve corrosion problems and simultaneously achieve light weight for metallic constructions, a combination of dissimilar alloyed galvanized sheet steel and aluminium is commonly used. The protective layer must satisfy the following conditions: be continuously adhering to the metal support, have uniform thickness and sufficient mechanical strength so as not to be destroyed during operation [1].

In the case of weld-brazing aluminium steel sheet, only aluminium melts in the joint. Thus, the filler material is chosen to be similar to the base material which is melted, considering the following characteristics: melting point, hardness, durability, electrical conductivity, and chemical composition, the flow of filler material and granulation of the filler material compared to the base material which does not melt. Such joints occur in electronics industry, in vehicles construction, and in supplies field [2].

Getting lighter structures using materials that until now could not be welded and therefore achieving lower consumption in operation (steel galvanized + steel galvanized, steel galvanized $+\mathrm{Cu}$ ).

\section{Experimental program weld-brazing CMTP and CMT of thin sheets of galvanized steel with aluminium}

\subsection{Base materials}

While conducting the experimental program following materials were used [3]:

*Corresponding author: gheorghe.sima@uav.ro 
- Galvanized steel sheet DX51D + Z150-NAC (SR EN 10327: 2004) 1mm thick.

- Aluminium alloy sheet EN AW 1200 (SR EN 1706: 2000) thick $1 \mathrm{~mm}$.

The main alloying elements that are found in aluminium alloys: copper, silicon, manganese, magnesium, lithium and zinc [4]. Elements such as nickel, chromium, titanium, scandium and zirconium can be added in very small amounts to achieve certain properties. Other elements can be found as impurities and these elements still have a significant contribution in changing or thermo-mechanical properties.

Filler alloy electrode was used, with wire diameter $1.2 \mathrm{~mm}$ AlSi5 using $\mathrm{cc}+$ polarity, the wire electrode EL-AlSi5 DIN 1732.

Pure argon was used as a protective gas (Ar 100\%), since aluminium alloys are suitable for the inert gas welding [5].

Using these base materials and filler materials with aluminium chemically predominant, $\mathrm{Al}$ and $\mathrm{Zn}$ will have the greatest influence in joints.

\subsection{Determining the type of dissimilar joints and weld-brazing variants}

The experimental program consisted of dissimilar joints making corner "overlap" because of the many applications that can be found in the field of machine manufacturing (auto, rail, etc.) $[6]$.

The experimental program aimed to obtain a structural and mechanical characterization of intermetallic layer formed from dissimilar joints made with different variants of weldbrazing conducted on two levels and the choice of specific parameters of weld-brazing technologies for joining galvanized aluminium alloy.

Table 1 presents the parameter values used to achieve heterogeneous galvanized steel joints - aluminium alloy.

Table 1 Values of parameters used to achieve joints.

\begin{tabular}{|c|c|c|c|c|c|c|}
\hline $\begin{array}{c}\text { Weld- } \\
\text { brazing } \\
\text { variant } \\
\text { number }\end{array}$ & $\mathrm{Is}[\mathrm{A}]$ & $\mathrm{U}_{\mathrm{a}}[\mathrm{V}]$ & $\mathrm{Vas}[\mathrm{m} / \mathrm{min}]$ & $\begin{array}{c}\text { CMT } \\
\text { CMTP** }\end{array}$ & $\mathrm{vs}[\mathrm{mm} / \mathrm{min}]$ & $\mathrm{Ina}^{*}$ \\
\hline 0 & 70.0 & 12.9 & 3.80 & CMT & 1000 & 5 \\
\hline 1 & 67.2 & 11.7 & 3.70 & CMT & 800 & 5 \\
\hline 2 & 88.6 & 15.2 & 4.37 & CMTP & 800 & 5 \\
\hline 3 & 88.6 & 15.2 & 4.35 & CMTP & 1000 & 5 \\
\hline $4 \mathrm{a}$ & 62.6 & 11.3 & 3.64 & CMT & 1000 & 5 \\
\hline $4 \mathrm{~b}$ & 62.6 & 11.3 & 3.64 & CMT & 1000 & 5 \\
\hline 5 & 61.0 & 11.3 & 3.47 & CMT & 800 & -5 \\
\hline 6 & 69.3 & 14.3 & 4.35 & CMTP & 800 & -5 \\
\hline 7 & 70.1 & 14.5 & 4.39 & CMTP & 1000 & -5 \\
\hline 8 & 63.6 & 11.6 & 3.69 & CMT & 1000 & -5 \\
\hline
\end{tabular}

* CMT Cold Metal Transfer ** CMTP Cold Pulse Transfer

In the experimental program were used $150 \times 250 \times 1 \mathrm{~mm}$ table sizes.

To optimize the process of weld-brazing with CMT process of galvanized aluminium sheets were selected the following influencing factors:

$-\mathrm{x}_{1} \rightarrow$ CMT transfer mode $*$ Cold Metal Transfer $* *$ CMTP Cold Steel Pulse Transfer

$-\mathrm{x}_{2} \rightarrow$ Welding speed $\mathrm{v}_{\mathrm{s}}[\mathrm{mm} / \mathrm{min}]$

$-\mathrm{x}_{3} \rightarrow$ Dynamic correction factor of spring $\mathrm{I}_{\text {na. }}$

It has been selected as objective function correlated analysis of the intermetallic layer by a factor of measurable tensile strength of the joint, while maintaining the function of the layer of zinc anticorrosion. 
The experimental program includes sampling mode and specimens needed to assess the structural and mechanical properties of heterogeneous connections (galvanized steel, aluminium alloy).

Figure 1 represents the procedure of the experiment on two levels with changing parameters determined in preliminary experiments.

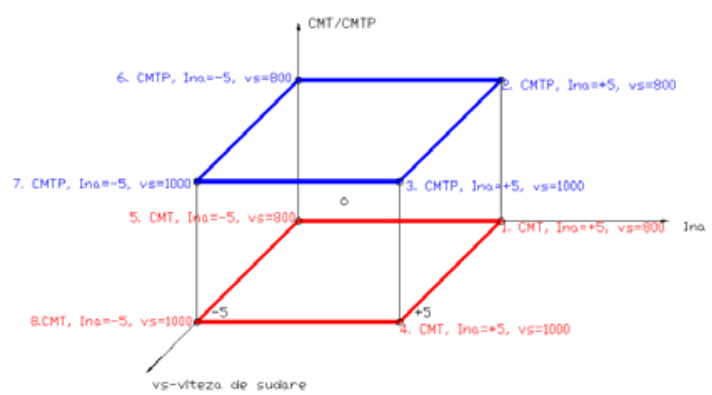

Fig. 1. Implementation plan on two levels factorial experiment. [2]

Positioning on samples plates weld-brazing micro-macro structural examination and tensile specimens (TRAC1, TRAC 2), bending (IND1 and IND2) for mechanical testing is performed according to standardized methodology.

\subsection{Macro and microscopic examination of the heterogeneous joint aluminium-zinc coated steel}

Macroscopic examination the cross sections of heterogeneous connections analysis showed no welding defects such as cracks, but 0 and 1 variants showed fine pores with a maximum diameter of $0.3 \mathrm{~mm}$ in the welded region (Fig. 2 and Table 2).

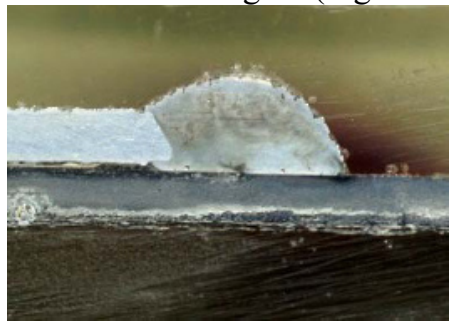

Fig. 2. Variant 0 of weld-brazing, made in the central point [Attack Nital 10\%]

Table 2 Macrostructures samples of the joints.

\begin{tabular}{|c|c|c|c|}
\hline $\begin{array}{c}\text { Sample } \\
\text { Test }\end{array}$ & Sample macro CMT & Sample Test & Sample macro CMTP \\
\hline $\begin{array}{c}\text { Version } 1 \\
\text { weld- } \\
\text { brazing } \\
\text { [Attack }\end{array}$ & & $\begin{array}{l}\text { Version } 2 \text { weld- } \\
\text { brazing [Attack } \\
\text { Nital } 10 \% \text { ] }\end{array}$ & \\
\hline Nital 10\%] & 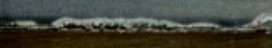 & & \\
\hline
\end{tabular}




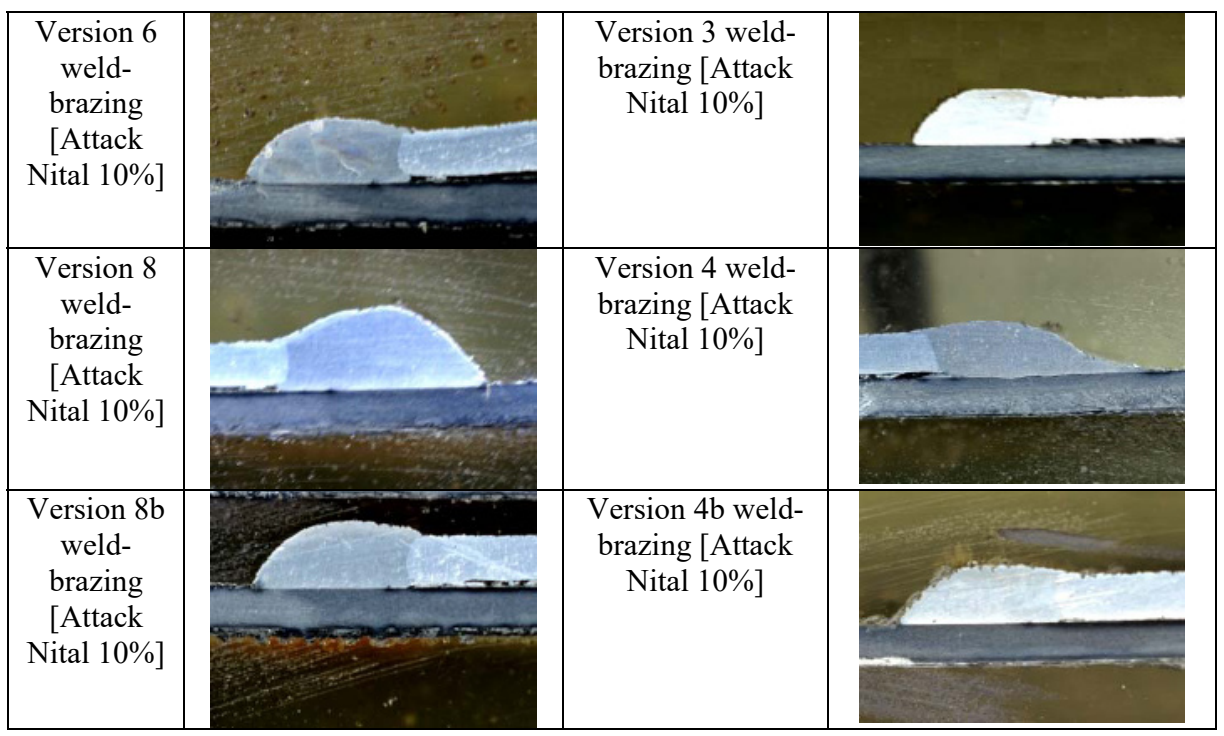

Over small beginning and final lengths of the weld-brazing process arc instability occurs resulting in uneven weld geometry, consequently it was considered necessary to remove the zone length of $50 \mathrm{~mm}$ using mechanical processes without excessive heating.

Figure 2 and table 2 present images of samples made in the 8 variants weld-brazing heterogeneous joints aluminium-zinc coated steel.

Analysing the visual connections made, it appears that the weld-brazing version 5 and weld-brazing version 8 heterogeneous presents defects in solder joints (sharp discontinuities) which are considered inappropriate, other variants showed no major defects, so are considered appropriate.

Microscopic examinations were performed in specific weld-brazing areas of heterogeneous connections (SUD, MB, ZIT) according to EN 1321: 2006 distinguishing the following structures (Fig. 3 and Table 3).

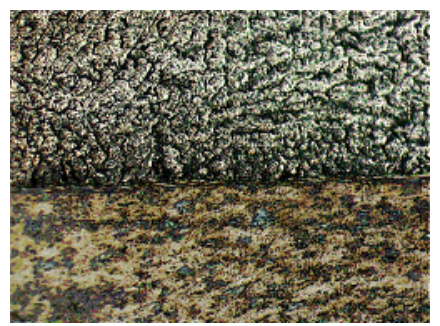

Fig. 3. Weld-brazing variant 0 [Attack Nital 2\%+5\% NaOH], 100x.

Table 3 Microstructure samples of the joints.

\begin{tabular}{|c|c|c|c|}
\hline Sample test & Macro sample CMT & Sample test & Macro sample CMTP \\
\hline Variant 1 & Variant 2 & \\
weld- & & weld- & \\
brazing & & brazing & \\
{$[$ Attack } & & Attack & \\
Nital $2 \%+$ & & Nital $2 \%+$ & \\
$5 \% \mathrm{NaOH}]$, & & $5 \% \mathrm{NaOH}]$, & \\
$100 \mathrm{x}$ & & $100 \mathrm{x}$ & \\
\hline
\end{tabular}




\begin{tabular}{|c|c|c|c|}
\hline $\begin{array}{c}\text { Variant } 6 \\
\text { weld- } \\
\text { brazing } \\
\text { [Attack } \\
\text { Nital } 2 \%+ \\
5 \% \mathrm{NaOH} \text { ], } \\
100 \mathrm{x}\end{array}$ & $\begin{array}{r}x \\
4 \\
4 \\
6\end{array}$ & $\begin{array}{c}\text { Variant } 3 \\
\text { weld- } \\
\text { brazing } \\
\text { [Attack } \\
\text { Nital } 2 \%+ \\
5 \% \mathrm{NaOH} \text {, } \\
100 \mathrm{x}\end{array}$ & 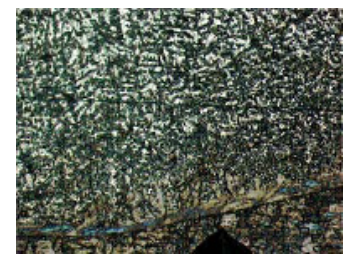 \\
\hline $\begin{array}{c}\text { Variant 8a } \\
\text { weld- } \\
\text { brazing } \\
\text { [Attack } \\
\text { Nital } 2 \%+ \\
5 \% \mathrm{NaOH} \text { ], } \\
100 \mathrm{x} \\
\end{array}$ & S. & $\begin{array}{c}\text { Variant } 4 \mathrm{a} \\
\text { weld- } \\
\text { brazing } \\
\text { [Attack } \\
\mathrm{Nital} 2 \%+ \\
5 \% \mathrm{NaOH} \text {, } \\
100 \mathrm{x} \\
\end{array}$ & 80 \\
\hline $\begin{array}{c}\text { Variant } 8 \mathrm{~b} \\
\text { weld- } \\
\text { brazing } \\
\text { [Attack } \\
\text { Nital } 2 \%+ \\
5 \% \mathrm{NaOH} \text { ], } \\
100 \mathrm{x} \\
\end{array}$ & 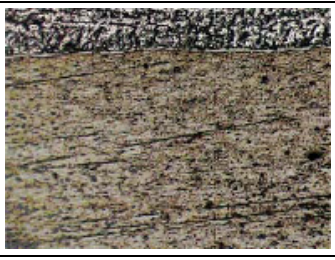 & $\begin{array}{c}\text { Variant } 4 \mathrm{~b} \\
\text { weld- } \\
\text { brazing } \\
\text { [Attack } \\
\mathrm{Nital} 2 \%+ \\
5 \% \mathrm{NaOH} \text {, } \\
100 \mathrm{x} \\
\end{array}$ & 48 \\
\hline
\end{tabular}

Conclusions result in the comparative study of the two levels: Weld-brazing the joint is achieved with the flattest CMTP compared with CMT. The same CMT process by changing only the dynamic correction factor $I_{n a}$ at +5 samples $4 \mathrm{a}$ and $4 \mathrm{~b}$ the cord is flatter, to $-58 \mathrm{a}$ and $8 \mathrm{~b}$ the cord more convex, in circumstances where the cord thickness does not change significantly.

As a result of this stage is noted that the CMT process gives flatter cords than CMTP and correction factor and it makes it less tall.

ZIT (heat affected zone) Areas examined microscopically showed no welding defects such as micro cracks and heat affected zones were clearly defined in the base material.

Primary dendrite is perpendicular oriented on interface at the CMT process, this show that the process structure cools faster than the CMTP.

At the process CMTP there is a greater flow of zinc in the aluminium, which explains the start fracture in this area.

Joint Some pores appear, but not outstanding defects. The structure is detrital, homogeneous, and harder than base material - aluminium. The cord ruptures are caused by initial cracks, due to a defect in the zinc layer. This is a common phenomenon at welded structure and galvanized later.

MB generally the basic material does not suffer structural diffusion; phenomenon encountered is zinc-silicon diffusion especially in aluminium.

\section{Conclusions}

Analysing the thickness of intermetallic is observed that they vary between 10-26 $\mu \mathrm{m}$, it appears that the CMT process intermetallic layer thickness is thinner than at the process CMTP (Sample 1 CMT, sample 2 CMTP).

As important conclusion of this work, thickness intermetallic layer must be maintained around, because the spacing of the aluminium atom allows migration of atoms of zinc. As a future conclusion it will be possible weld-brazing of those dissimilar materials on which atoms of one material can migrate on the network of the other material. 
It is observed from the thickness study and from analysis of the breaking strength at the transfer CMT the intermetallic layer is thinner and breaking strength [4] is increased. As a result when using materials with brittle intermetallic layers give recommended procedure weld-brazing CMT. If we weld-brazing similar materials that do not give CMTP preferred intermetallic layer which introduces a superior linear energy and make mechanical connections formed to be stronger and joints have required mechanical characteristics.

In the base metal (carbon steel) fine ferrite-pearlite structure with oxide inclusions, perlite is placed it in general within grains. In the base metal (aluminium alloy) structure composed of $\alpha$-rich solid solution in aluminium, results Al-Si intermetallic compounds and oxides of aluminium.

In the interface between the galvanized steel and weld are noted intermetallic layers of different thicknesses that separate the two areas.

The welds (SUD) made by the process of CMT or CMTP dendritic structure grows with specific structures zinc-aluminium alloys, $\alpha$-solid solution and intermetallic compounds of silicon.

Acknowledgements: Research Contract ISIM Timisoara, PN 09-160103, 01.03.2009 Electric arc weld brazing in shielded gases, coordinator Dragut, $\mathrm{L}$

\section{References}

1. S. Kroger, R. Killing, Software for creating and managing parameters for MIG/MAG welding. German Welding Assoc. Yearbook, DVS-Verlag, 150-161 (2004)

2. R. A. Rosu, D. R. Pascu, E. Muncut, C. Toma, ModTech 2011 Intern. Conf. Proceedings, Republic of Moldova, 929 (2011)

3. G. Trommer, Sudura Review, 20, 1 (2010)

4. E. Muncut, R. Lile, Gh. Sima and D. Glavan, Pensee Journal, 76, 5 (2014)

5. G. Mathers, The welding of aluminium and its alloys, Ch.3 (Woodhead Publishing Limited, Abington Hall, 2002)

6. ***. CMT: Cold Metal Transfer MIG/MAG dip-transfer process for automated applications. (Fronius International, 2005)

7. S. Kodoma, Y. Ishida, K. Asai, M. Mizumoto, T. Namekata, H. Nagasaki, Welding in the World, 54, 328-336 (2010) 